\title{
La estructura conflictiva del Ereignis. Una lectura de la donación y la diferencia en el fenómeno heideggeriano
}

\author{
The conflicting structure of Ereignis. \\ An analysis of Givenness and Difference \\ in the Heideggerian phenomenon
}

\author{
LETICIA BASSO MONTEVERDE \\ CONICET - Universidad Nacional de Mar del Plata, (Argentina).
}

Recibido: 15-11-2010

Aprobado definitivamente: 02-02-2011

\section{RESUMEN}

Este escrito se aproxima al fenómeno del Ereignis, tema que Heidegger desarrolló en su pensamiento posterior a la Kehre para trabajar el problema del ser como acontecer. El trabajo plantea la estructura conflictiva del Ereignis con el fin de dar cuenta de la tensión inmanente al fenómeno y analizar su constitución por medio de las dimensiones que en él se tensionan. Esta lectura muestra el origen de la tensión en la oscilación del Ereignis y refiere su sentido a la donación del ser.

\author{
PALABRAS CLAVE \\ HEIDEGGER - EREIGNIS - DONACIÓN - DIFERENCIA
}

\begin{abstract}
In this paper we approach the phenomenon of Ereignis, an idea that Heidegger developed after his Kehre to elucidate the problem of Being as enowning. We highlight the conflicting structure of Ereignis in order to indicate the immanent tension of the phenomenon and we analyze the dimensions of its constitution. Finally, this work shows Ereignis' tension and refers its meaning to the notion of Givenness of Being.
\end{abstract}

\author{
KEY WORDS \\ HEIDEGGER - EREIGNIS - GIVENNESS - DIFFERENCE
}

(C) Contrastes. Revista Internacional de Filosofía, vol. XVII (2012), pp. 27-45. ISSN: 1136-4076

Departamento de Filosofía, Universidad de Málaga, Facultad de Filosofía y Letras Campus de Teatinos, E-29071 Málaga (España) 


\section{INTRODUCCIÓN}

ESTE ESCRITO SE APROXIMA al fenómeno del Ereignis, tema que Heidegger desarrolló en su pensamiento posterior a la Kehre para trabajar el problema del ser como acontecer. El trabajo plantea -principalmente a partir de las obras Beiträge zur Philosophie (vom Ereignis), Zur Sache des Denkens y Unterwegs zur Sprache- la estructura conflictiva del Ereignis con el fin de dar cuenta de la tensión inmanente al fenómeno y analizar su constitución por medio de las dimensiones que en él se tensionan. Esta lectura nos permite mostrar el origen de la tensión en la oscilación del Ereignis y retroensamblar su sentido en la donación del ser.

Para esto el escrito se divide en cuatro partes: la primera aborda el abismo de lo inaparente en su falta de fundamento. La segunda parte describe la noción del Ereignis desde su génesis etimológica. Luego, la tercera parte elabora la estructura conflictiva a partir de las dimensiones que la componen y, por último, la cuarta parte comprende la articulación del camino heideggeriano a través de la continuidad del proyecto de la década del '20 al '30, acentuando las ideas de la diferencia y la donación del ser.

\section{El ESENCIARSE DEL SER}

\section{1. CÓMO PENSAR EL ABISMO}

A lo largo de la obra de Heidegger y especialmente después de la Kehre se puede observar que la cuestión del ser deviene en la diferencia ontológica. Para el autor esto se debe, en principio, a que la problemática del sentido del ser condujo a una determinación entificadora. De allí se desprende la necesidad de mostrar cuál es la esencia del ser. Heidegger intuye que la causa de este problema no se reduce a la acción del hombre, pues no es el hombre el que confunde ser por ente. Por el contrario, ya el ser se esencia como ente y de allí emerge la paradoja en cuestión. Si el problema del ser es el problema de la diferencia ontológica y su origen se encuentra en el esenciarse del ser, toda reflexión que pretenda descubrir su sentido debe analizar la génesis y constitución de este despliegue.

El filósofo considera que el método pertinente para realizar esta tarea es la fenomenología, porque ella nos muestra de forma natural aquello ante lo cual nos conducimos. De esta manera la fenomenología posibilita una aprehensión directa de la esencia del ser en su esenciarse, es decir, que descubre la diferencia. Ahora bien, por medio de una fenomenología de lo inaparente (eine Phänomenologie des Unscheinbaren) Heidegger anuncia el abismo (Ab-grund) del esenciarse. Para el autor la idea de un abismo apunta a la carencia de un fundamento determinado que trascienda y, a la vez, contenga la instancia de la donación. Así, el abismo expresa el lugar donde el ser reposa y se activa en la 
dinámica del acontecer, ya que la verdad se despliega en la donación sustraída que muestra y oculta el sentido del ser. Por otro lado, lo inaparente refiere a la imposibilidad de una caracterización acabada del sentido del ser debido a su condición inefable. En cuanto a que la inagotabilidad de la destinación genera un resto que excede a toda aprehensión y que por la ausencia de lo presente impide su definición.

El ser se muestra en el ente y deviene en aquello que enmascara su esencia. Por consiguiente, su origen es la ocultación (Verbergung) y la desocultación (Entbergung) es un fenómeno derivado. No obstante el filósofo indica que tanto el encubrimiento como su opuesto son las dos caras de lo que se da. De allí se sigue que toda experiencia evoque a ambos y contenga las dos partes de esta unidad. Mas aún ¿qué se da? ${ }^{1}$ Heidegger dice en su conferencia Zeit und Sein que se da el ser y se da el tiempo (Es gibt Sein und es gibt Zeit). El dar es la donación permanente que como toda presencia (Anwesenheit) de lo presente en un punto se oculta. La presencia de lo presente es el ser que no «es» sino que se «da» y, como tal, no puede predicarse. En este sentido, «lo que se oculta» es el ser en el ente y -en una de sus formas- lo que puede ser y en dicho ente no se anuncia. Por tanto, como decíamos, lo no predicable es la donación. Aunque, a la vez, el ser como don no queda al margen del dar y, de este modo, el dejar-estar-presente es desocultar porque el don queda retenido en el dar y en su receptor se desoculta. ${ }^{2}$ Sin embargo en el protocolo al seminario Zeit und $\operatorname{Sein}^{3}$ Heidegger afirma que como todo dar es también dejar-estar-presente «lo que está presente», aquí se mienta la diferencia en el modo del pensar metafísico. En tal caso, para el filósofo es fundamental 1) distinguir el doble sentido del dejar-estar-presente como simple dejar o como dejar algo y 2) asumir en el Ereignis la dificultad de confiar al pensar la diferencia.

Por último introducimos la siguiente pregunta ¿qué función tiene el tiempo en el dar del ser? Según Heidegger, si entendemos al ser como acontecer y no

1 El verbo «dar o donar» implica un objeto directo y otro indirecto, es decir, se da algo a alguien. La expresión «se da» (Es gibt) refiere a la disponibilidad de lo que se dona, de forma tal que involucra tanto el grado de disponibilidad de lo ofrecido como también un destinatario en el acto mismo de la donación. Por otro lado, «se da» es una expresión impersonal, por lo que no hay un sujeto definido que efectúe la acción. En este caso, es más valiosa la acción que su agente y pareciera que esta acción requiere de un receptor pero no de un emisor determinado. Entonces, se puede inferir que la donación impela su recepción pero disipa toda respuesta más allá del acto en cuestión.

2 cf. M. Heidegger, Zur Sache des Denkens [GA 14], Vittorio Klostermann, Frankfurt am Main, 2007, p. 9. (Tiempo y Ser, trad. Garrido, Molinuevo y Duque, Tecnos, Madrid, 1999, pp. 24-25.)

3 Véase M. Heidegger, Zur Sache des Denkens [GA 14], op. cit., pp. 45-46. (Tiempo y Ser, op. cit., pp. 56-57.) 
como entidad, se descubre el tiempo como aquello a través de lo cual se manifiesta. Entonces, a pesar de que el ser no requiere de un sostén entitativo, sí se funda en el tiempo que es la condición de posibilidad de su esenciarse.

\section{2. EL TRÁNSITO AL SER}

Heidegger formula el tránsito del pensar hacia «otro comienzo» para lograr un acceso fiel al esenciarse del ser. El tránsito nos repone en el origen de la donación de forma tal que se entienda tanto su envío como su sustracción. De este modo el «otro comienzo» tiene la tarea de restablecer la oscilación (Schwingung) propia del ser en un pensar que revele la indigencia del anterior porque el ocultamiento es una dimensión del Ereignis.

Más allá de reconocer el «olvido del ser» (Seinsvergessenheit) el hombre debe entender el sentido de la diferencia ontológica. Este aspecto no refiere a la auténtica comprensión del ser, sino a la importancia de abrirnos a la superación de la diferencia a través de la aceptación de la oscilación. En efecto, la verdad implica la no-verdad (Un-Wahrheit), allí reside el punto en cuestión.

Con el fin de descubrir la indigencia del pensar Heidegger programa la Historia del ser. Este proceso retoma la tradición filosófica para de-construir y criticar cada figura epocal porque en ellas aún se encuentra un resto del origen. El pensar del ser, a diferencia del pensar de la metafísica, no ejerce la vía objetiva de la representación porque la modalidad del otro comienzo proyecta una meditación y actitud del dejar-ser. Por medio de un pensar exploratorio y espontáneo Heidegger propone sondear (Er-gründen) lo abismal para afrontar la obstrucción del ser y restablecer al Dasein en la retención. De esta manera el ahí del ser capta las señas y funda la verdad.

Hemos indicado que el ser no puede entenderse por medio de la representación, dado a que todo concepto exhibe un sentido que denota algo, a saber, qué es el ser. Heidegger explica que si el ser refiere a lo que acontece, éste no puede comprenderse a partir de una lógica atributiva. Por tanto, de acuerdo a los aspectos del hacer señas y de la captación del ser podemos recordar que toda búsqueda de sentido no debe apuntar a un qué sino aún cómo. De esta manera, si el ser no es algo, la seña describe la figura de la emisión, a saber, el envío de lo que dona, este es un sentido de la seña. Luego, el hombre debe captar lo que la seña expresa de forma pasiva por la recepción, puesto que de otro modo se deformaría el expresar de la seña.

Si nos adentramos en el tema de la captación del ser, el pensamiento posterior a la Kehre reformula el lenguaje (Sprache) en dirección al método de la sigética. Cuando Heidegger desarrolla estas cuestiones busca vincular su concepción del lenguaje del ser con el abismo, lo inaparente y la oscilación. Bajo esta óptica el lenguaje pretende identificarse con el pensar, por lo pronto, a partir 
de un paralelo con la experiencia. Hay una identidad entre el ser y el pensar, y ésta es el Ereignis -ya lo decía Heidegger en Der Satz der Identität. ${ }^{4}$

En el protocolo al seminario Zeit und Sein, Heidegger afirma que el Ereignis debe ser experimentado en la seña y no demostrado. En otros términos, si el lenguaje es la forma de mostrar el ser, éste debe emplazarse en el otro comienzo, de allí se sigue que la palabra que lo enuncie se inscriba en el quiebre. La figura del quiebre indica la barrera que impide representar el sentido del ser, en tanto lo comprendamos como el abismo y la oscilación de su esenciar. El quiebre intenta dejar de lado la función habitual de la palabra, es decir, que la palabra no sea un producto arbitrario establecido de una forma regulada para referirse a un entidad externa bajo una unidad de sentido. La palabra quebrada, por el contrario, es junto a la experiencia y deviene una con ella pues allí se funda el mundo. Esta palabra más que enunciar escucha porque desplaza su esencia de la agencia humana al llamado del ser, por esto Heidegger recurre a la palabra del poeta.

Una vez planteado, a grandes rasgos, el contexto del pensar de Heidegger después de la Kehre y el abismo que la fenomenología de lo inaparente propone, nos interesa describir la composición del Ereignis en el contexto del pensamiento heideggeriano. Aunque creemos necesario primero exponer de forma sintética el sentido del término en sí, puesto que no es lo mismo su origen etimológico que aquello que el autor intenta decir con él. Por otro lado, es importante también destacar las diversas traducciones que se han hecho al español del término para, de esta forma, delimitar mejor a qué se refiere el autor con el Ereignis.

\section{EL FENÓMENO DEL EREIGNIS \\ II. 1. LA GÉNESIS DEL TÉRMINO}

El término Ereignis en el pensamiento heideggeriano porta una carga significativa realmente compleja que excede al sentido y la referencia de la palabra en su contexto habitual. De esta manera, como es usual en el discurso del autor alemán, se torna difícil reinterpretar o traducir, incluso en lenguaje filosófico, las nociones del autor. Muchas veces, pese a su discrepancia con el uso de algunos términos, Heidegger pone a prueba ciertas palabras y las emplea a falta de otras opciones. Aunque en otras circunstancias, a lo largo de sus obras, las palabras varían a medida que su búsqueda evoluciona y alcanza un grado de conformidad con el término que exprese de forma considerable aquello que él quiere mostrar.

4 Véase, M. Heidegger, Identität und Differenz - Identidad y Diferencia, [GA 11] edición bilingüe, trad. H. Cortés y A. Leyte, Anthropos, España, 1990, p. 91. 
En el caso del Ereignis es importante destacar que con este término el filósofo intenta describir un fenómeno, algo que acontece en la experiencia y que justamente se comprende a través de su viviencia. Por tanto, Ereignis no indica una noción que trascienda la realidad y corresponda a un sistema teórico. De este modo Heidegger dice al inicio de los Beiträge: «Ya no se trata más de tratar 'sobre' algo y de presentar algo objetivo, sino de ser transferido al Er-eignis, lo que equivale a un cambio esencial del hombre de 'animal racional' (animal rationale) al ser-ahí». ${ }^{5}$ La dificultad yace en la idea de expresar un fenómeno singular que caracteriza la relación más esencial e íntima entre el hombre y el ser. Como dice Manuel Garrido en su introducción a la traducción de Zur Sache des Denkens «[...] la conferencia 'Tiempo y Ser' [...] está dedicada a desarrollar finalmente una idea/experiencia que Heidegger denomina Ereignis, [...] de aquí podría inferirse que la intención de Heidegger es poner de relieve el carácter eminentemente procesual y dinámico de su ontología». ${ }^{6}$

Heidegger juega con la profundidad del Ereignis y los diversos niveles de sentido que el término tiene en un diálogo continuo con los matices que su origen etimológico nos brinda. Por ejemplo, Garrido nos comenta que, a través del juego filológico que lo caracteriza, Heidegger plantea que al descomponer el vocablo alemán en Er-eignis se puede observar que el prefijo «Er» indica un matiz intensivo y la parte «eignis» puede derivar de «eigen» que en alemán significa «propio». Este motivo le permite a Heidegger desviar el sentido ordinario del término «acontecimiento» hacia el influjo semántico de la apropiación.

Por otro lado, Irene Borges Duarte comenta en la introducción a un escrito de von Herrmann ${ }^{7}$ que la procedencia etimológica de Ereignis de eräugen, que significa captar con la mirada, pero también poner a la vista y mostrar, mostrarse y acontecer, relaciona lo propio con la idea de lo propicio. Esto se debe a que «eräugen expresa lo que acontece en el instante (Augen-blick) de hallar con la mirada lo que se a-delanta a ser mirado: el propiciarse de la visión». ${ }^{8}$ De este modo, Borges Duarte reconoce la agudeza de Félix Duque al traducir Ereignis por «acaecimiento propicio» y destaca que «lo propicio propicia y lo así propiciado es lo propio y apropiado del ser-ahí», ${ }^{9}$ por tanto Borges Duarte recalca como el Ereignis busca ser él mismo Ereignis.

5 M. Heidegger, Beiträge zur philosophie (Vom Ereignis) [GA 65], Vittorio Klostermann, Frankfurt am Main, 1989, p. 3. (Aportes a la Filosofía. Acerca del evento, trad. Dina Picotti, Almagesto y Biblos, Buenos Aires, 2003, p. 21.)

6 M. Heidegger, Tiempo y Ser, op. cit., p. 15.

7 F. W. von Herrmann, La segunda mitad de Ser y Tiempo. Sobre los problemas fundamentales de la Fenomenología de Heidegger, Trotta, Madrid, 1997. pp. 9-20

8 F. W. von Herrmann, op. cit., p. 20

9 Ibid. 
Finalmente, Garrido subraya un problema en las traducciones del término al español, inglés y francés ${ }^{10}$, a saber, que éstas no denotan en ninguna de sus formas o sinónimos ni el origen etimológico de la apropiación ni el de lo propicio. Por tanto las soluciones posibles a este problema -fuera del uso corriente del término sin la impronta semántica heideggeriana-suelen ser dos: la primera es mantener el uso del término alemán en las traducciones o escritos referidos al tema -ésta es la modalidad que emplea el presente trabajo- y la segunda opción es traducir el término de forma tal que dé cuenta de estos matices. Esta última se ha llevado a cabo de diversas formas, por ejemplo algunas de las traducciones españolas son acaecimiento propicio, advenimiento apropiador, acaecimiento apropiador, acontecimiento apropiante y evento apropiador, entre otras.

Volviendo al sentido del término en la reflexión heideggeriana en torno a la experiencia de este fenómeno podemos retomar un pasaje de Zeit und Sein en el que Heidegger aclara: «Lo nombrado con el nombre alemán das Ereignis no podemos representárnoslo ya tomando como hilo conductor el significado usual de la palabra; pues éste la entiende en el sentido de evento (Geschehnis) y suceso (Vorkommnis) no desde el apropiarse como esclarecedor y salvaguardante extender y destinar». ${ }^{11}$ Recordemos que Heidegger ya afirma en una de sus primeras lecciones de Friburgo, Die Idee der Philosophie und das Weltanschauungsproblem,${ }^{12}$ que el neokantismo habla de un proceso o suceso (Vorgang) para referirse a la idea de vivencia dentro del esquema sujeto-objeto, es decir, demarcando su carácter gnoseológico y disgregando sus partes para establecer la validez objetiva de su sentido en el plano de la desmundanización del fenómeno. En su búsqueda de un método para acceder a lo originario Heidegger se detiene en el concepto de vivencia (Erlebnis) y para eludir sus raíces psíquicas, en contra de lo propuesto por esta escuela, describe la estructura de esta noción como Er-eignis, un acontecimiento en el que el yo y lo vivido se implican. De este modo, Heidegger busca renovar el sentido gastado del término «vivencia» para reflexionar acerca de lo que «se da» (es gibt) en esta instancia. Bajo esta óptica, el autor descubre que el primer sentido que asoma en la vivencia refiere a la facticidad, es decir, que en ella no experimentamos ni un yo ni el sentido objetivo de algo sino que todo acontece en la apropiación y remisión directa. Por otro lado, la constitución del Er-eignis esta determinada por la noción del

10 Bajo los términos evento, event, événement.

11 M. Heidegger, Zur Sache des Denkens [GA 14], op. cit., pp. 25-26. (Tiempo y Ser, op. cit., p. 40.)

12 Específicamente de los $\S \S 13$ al 15 de «Die Idee der Philosophie und das Weltanschauungsproblem» en Zur Bestimmung der Philosophie [GA 56/57], Vittorio Klostermann, Frankfurt am Main, 1987. (La idea de la filosofía y el problema de la concepción de mundo, trad. Jesús Adrián Escudero, Herder, Barcelona, 2005, pp. 80-92.) 
haber previo (Vorhabe) que luego el hombre actualiza en la reconfiguración del sentido de la vivencia. De aquí se sigue que la experiencia del Ereignis tenga en sí el peso de la tradición y sin embargo pueda proyectar una vivencia auténtica, porque el sentido se transforma en función a la experiencia que acontece.

Ahora bien, la reflexión heideggeriana de la década del '20 no puede homologarse al tratamiento, la profundidad y orientación que en los '30 Heidegger le da al Ereignis a través de la Kehre, no obstante no puede negarse que en germen ya se encuentra un poco de esta caracterización. Por ende, retomando la expresión del Ereignis podemos ver que esta torsión del término refleja incluso en otro período de la obra del autor la relación tensional -entre el hombre y el ser, la tradición (lo constituyente) y lo dado (lo constituido) - a partir de la cual el filósofo intenta mostrar la génesis y dinámica del fenómeno.

\section{2. DERIVAS SEMÁNTICAS DEL EREIGNIS}

En cuanto a los sentidos derivados del término Ereignis Roberto Walton plantea, ${ }^{13}$ siguiendo la reflexión de Heidegger, dos vertientes de interpretación: una que asocia el término con un posible diálogo entre el Dasein y el Seyn, y otra que recurre al símil de la mirada para decantar su sentido.

En torno a la primera interpretación Walton explica que una forma de entender la oscilación que va del Dasein al Seyn y del Seyn al Dasein es a través de un paralelo con la figura de la conversación (Gespräch). Así la relación esencial implica, tal como la conversación, la necesidad de la unidad y el equilibrio a través de un punto medio. De este modo, la escucha (hören) del Dasein para la pertenencia al Seyn adviene de la interpelación (Anspruch) de este último en el llamado. A propósito podemos señalar que para Heidegger ambos elementos acontecen en la unidad y se complementan de forma tal que uno no existe sin el otro. Tanto el Dasein como el Seyn son en la relación, pues ninguno de estos pre-existe a la instancia del Ereignis. En este sentido, el hombre requiere ser despertado por el llamado del Seyn, incluso Heidegger señala que un golpe (Stoss) es el que lo repone en la donación, y el Seyn precisa del hombre porque sólo encuentra su clarificante expresión a través de él. Es decir, que el Dasein lo mantiene presente en la custodia de su verdad. En Der Satz der Identität ${ }^{14}$ Heidegger señala que la «mutua pertenencia» (Zusammengehören) debe acentuar el segundo término, la pertenencia, porque lo mutuo es ahora determinado a partir de ella. Seguido plantea que «se debe experimentar lo mutuo a partir

13 En su seminario doctoral "Los modos del acontecimiento y el horizonte de mundo" dictado en el marco del Doctorado en Filosofía, Universidad de Buenos Aires, 2010.

$14 c f$. M. Heidegger, Identität und Differenz - Identidad y Diferencia, [GA 11], op. cit., p. 73 
de la pertenencia ${ }^{15}$ porque en ella se funda la dimensión de lo simple en la relación hombre y ser.

Ahora bien, acerca de la segunda vertiente Walton nos transmite - tal como Borges Duarte- que Heidegger también apela a la mirada para mostrar el sentido de la relación. Sobre este tema vale recordar que Heidegger desde los '20 describe el método del acceso a lo originario por medio de la mirada. En este primer período el filósofo detalla el comportamiento (Verhalten) del Dasein para una comprensión auténtica del ser por medio de tres coordenadas que en sus obras tempranas adquieren diversas formas, un ejemplo de estas tres coordenadas es el Blickstand, Blickrichtung y Sichtweite, a saber, punto, dirección y horizonte de la mirada desarrolladas en el Natorp Bericht. ${ }^{16}$ Aunque puede destacarse una diferencia acerca de la modalidad de la mirada en ambos períodos, puesto a que en los '20 Heidegger expone estas coordenadas apuntando a su carácter de ejecución y cuidado. Por el contrario, la mirada de los '30 es la del dejar ser y la nota que la caracteriza no es la ejecución en la praxis sino que se destaca la idea de la contramirada, a saber, la mirada receptiva que capta lo que acontece fuera de la validación en cierto punto objetiva que Heidegger profesaba todavía en los '20. Entonces, retomando lo que Walton describe podemos acudir a sus palabras: el hombre avista (er-blickt) el ser, o alcanza el ser con la mirada, y a la vez el ser nos avista de moda que hay un recíproco avistarse. De esta manera y como ya vimos, la procedencia etimológica le permite a Heidegger relacionar además del término er-eignen con la apropiación, el término er-äugnen que originariamente es avistar, pues se relaciona con el término Auge, ojo. Por otro lado, Walton rescata de Heidegger que avistar no significa simplemente ver (sehen) algo sino que el verbo reposa en mirar hacia lo que, desde lo visto, nos dirige la mirada propiamente. Tal como vimos con el matiz de lo propicio en la connotación etimológica del Ereignis.

A continuación analizaremos la constitución del Ereignis a fin de mostrar, dentro de lo posible, las dimensiones de su estructura conflictiva.

\section{LA ESTRUCTURA CONFLICTIVA DEL EREIGNIS}

Fuera de los influjos filológicos, una aproximación a los Beiträge nos permite rescatar la provocación que entre Seyn y Dasein emerge. Si nos introducimos en la obra y logramos, a pesar del discurso reiterativo y poético del autor, reconocer las tensiones que en cada ensamble se presentan, será posible

15 Ibid.

16 Otras formas de las coordenadas son la Vorhabe, Vorgriff, Vorsicht (haber previo, preconcepción y pre-visión) en Sein und Zeit [GA 2] y Rücksicht, Hinsicht y Absicht (consideración del pasado, atención al presente e intención del futuro) en Die Grundbegriffe der Metaphysik [GA 29/30]. 
reconstruir la estructura del Ereignis. De forma tal que por medio del problema de la donación del ser, de su oscilación y extravío, se perciba tanto el origen como la constitución del fenómeno.

Ciertamente allí, donde la tensión vincula ambas partes -Seyn y Dasein-de forma no dual, surge la provocación alternante (wechselseitigen Herausforderung) que por causa de la apropiación (Er-eignung) y expropiación (Ent-eignung) compone y descompone la diferencia. El filósofo evita hablar de lo dual porque esta modalidad no hace más que realzar la separación como fenómeno originario y, de hecho, sólo podemos hablar de una distinción como efecto de la unidad e intimidad de la diferencia. Incluso en Der Satz der Identität,${ }^{17}$ como ya mencionamos, Heidegger insiste en que la mutua pertenencia de hombre y ser debe comprenderse en una dimensión para no ejercer la violencia de la separación de un orden conjunto por la coordinación e integración de las partes. Ser y ente son uno, es decir, tienen sentido en el acaecer conjunto y no en una fusión derivada. Por tanto, en este nivel de la donación se transgrede toda concepción de entidad asilada para ir más allá de la disociación. Esta búsqueda de la unidad brinda el equilibrio en la correspondencia ser-ente y, en consecuencia, la identidad del fenómeno ontológico.

No obstante este trabajo propondrá, una vez establecida la idea de que la estructura del Ereignis se define por la intimidad de sus partes, un análisis de la constitución del fenómeno a partir de sus dimensiones. Esto se debe a que la mejor forma de mostrar la dinámica del Ereignis resulta de la descripción de la función de sus partes. De este modo el Ereignis se caracteriza por la tensión de sus partes que en su punto medio (Mitte) transitan, por la expropiación de sí, a la concreción de su esencia para acceder a la pertenencia. Esto se debe a que sólo en el entre (Zwischen) ocurre la puesta en obra de la verdad. En la conferencia Die Sprache Heidegger explica que las partes se atraviesan y forman un medio en el que concuerdan y son íntimas. Así, por la intimidad, las partes se distinguen porque en el entre reside la diferencia, el inter-medio (Unter-Schied). ${ }^{18} \mathrm{La}$ diferencia es una y unitiva, y por ella se concreta toda obra. Heidegger incluso dice que la diferencia es la dimensión donde adviene el Ereignis.

Ahora bien, la idea de dimensión en el pensamiento de Heidegger tiene dos sentidos, tal como el Ereignis oscila en dos instancias. El filósofo entiende a la dimensión como el lugar de lo calculable relacionado a lo ente o como el lugar de lo originario donde el ser mora. Esta segunda acepción de la dimensión acerca del origen apunta también a la actividad vital del Dasein en el despliegue del Seyn, puesto a que -de acuerdo a la influencia aristotélica en el pensador 75.

17 cf. M. Heidegger, Identität und Differenz - Identidad y Diferencia [GA 11], op. cit., p.

18 cf. M. Heidegger, De camino al habla [GA 12], op. cit., p. 22. 
alemán- la dimensión, el tiempo y el movimiento están relacionados. Nosotros referiremos aquí a esta última acepción de dimensión porque nos interesa reforzar la dinámica del Ereignis.

Entonces, la estructura del fenómeno parte de la instancia originaria de la donación. Como ya mencionamos en la primera parte de este escrito la donación se desdobla en el donar y lo que dona, y por tanto se compone del ser y el ente. La oscilación que define la dinámica del fenómeno proviene de la paradoja del ser en la donación, ya que en el claro-oscuro se oculta y desoculta el sentido del ser. De aquí se infiere el conflicto que constituye las dimensiones del fenómeno. La idea del conflicto ${ }^{19}$ en el fenómeno indica el cruce de niveles de significación opuestos en la relación ser-ente. Esto quiere decir que el conflicto consiste en las dimensiones tensivas del Ereignis. Por otro lado, aunque en referencia a lo planteado, la idea de una estructura conflictiva integra la composición del Ereignis a partir de la tendencia singular no a la exclusión de los opuestos sino a la armonía de los contrarios. Este conflicto, a diferencia de la idea de un dilema, descubre que el fenómeno se realiza en el balanceo constante de las dimensiones y no en la selección de una de éstas. Sin duda alguna Heidegger plantea esta dinámica tensiva con el fin de abrir la cuestión del ser al problema de la diferencia, puesto que la perspectiva de la tensión, oscilación y extravío posibilita una comprensión superadora.

En otras palabras, la presencia de la oscilación se adhiere al objetivo de abarcar al Ereignis en sus dimensiones sin socavar el camino a ningún ámbito ontológico, puesto que el extravío en que se encuentra el saber esencial da a entender cómo acoger al ser en la condición de acaecer temporal es desplegar las posibilidades de encontrarse en la verdad y en la no verdad. Por lo demás, basta con experimentar el quiebre para despertar y permanecer en «el entre» del Ereignis, ya que recién en el extravío que enlaza el abismo dimensional podrá el Dasein meditar acerca del vacilante transcurso del Seyn. Por consiguiente, se entiende que estar en la verdad es estar en la lucha esencial, no la guerra violenta por la puja dominante sino la contienda en la provocación y desafío entre el hombre y el ser. De esta manera como dice Heidegger, al ser no se arriba por una espera creyente porque éste exige de nosotros la perseverancia en la larga preparación que ha de soportar la reticencia del ser en su donación.

En un primer momento, siguiendo los delineamientos aquí presentes, podemos establecer que la estructura general del Ereignis se compone de dos dimensiones que expresan la donación y sustracción de lo que acontece. De aquí

19 Acerca dec las nociones de conflicto, estructura, dilema, antinomia se ha cotejado el escrito de Ricardo Maliandi «Conflictividad y convergencia en bioética» en C. Barrio; L. Basso, Reflexiones éticas para una sociedad en transformación, Actas de las IX Jornadas Agora Philosophica, Biblioteca electrónica AAdIE, Mar del Plata, 2009, pp. 426-439. 
se sigue que cada dimensión refiere a la relación Dasein y Seyn. A continuación esbozaremos los rasgos iniciales que conforman el fenómeno, de esta manera dejamos pendiente para una futura investigación el detalle de la dinámica de las dimensiones que componen el Ereignis.

De acuerdo a la dinámica tensiva de la donación entendemos que estas dimensiones transcurren respecto a lo que se considera una deformación del sentido del ser o la develación de éste. De esta manera, bajo las formas ${ }^{20}$ de la yección (Zuwurf) del Seyn y la proyección (Entwurf) del Dasein, el Ereignis despliega la verdad en la dimensión de la develación. En este caso, la yección aconteciente del Seyn impela al Dasein a captarla. Esta yección arrebata al $D a$ sein de la caída y lo enfrenta a la inmensidad del llamado, produciendo primero el espanto. Luego, el Dasein es despertado y por la proyección acontecida se recupera en el sí mismo y efectúa la reapropiacion(Vereignung). De este modo, el llamado (Zurufo Anruf) del Seyn y la pertenencia (Zugehörigkeit) del Dasein consisten en dos formas de realización auténtica.

Por otro lado, cuando la yección se sustrae y la proyección deviene en caída, la verdad se oculta en los ropajes del ente, a saber, la dimensión de la deformación. En estos ámbitos no se efectúa ni el viraje (Kehre) del Dasein ni el contraviraje (Wider-kehre) del Seyn. Fuera de toda retención en el "ahí del ser" y lejos del contraimpulso (Gegenschwung) que abre al Dasein a la captación, la donación permanece encubierta en el Enteignis. Sin embargo, a la hora de presentar la estructura general de la donación hay que recordar que el Ereignis se compone de estas dos dimensiones. ${ }^{21}$ Por esto en la puja contraoscilante (Gegenschwingend) de la yección del Seyn y la proyección del Dasein, y del rehusamiento (Verweigerung) de la yección y el abandono del ser (Seinsverlassenheit), emerge el Ereignis.

\section{A MODO DE CONCLUSIÓN. LA ARTICULACIÓN DEL CAMINO HEIDEGGERIANO}

Para analizar la continuidad del pensamiento de Heidegger de la década del '20 al '30 retomaremos, en esta parte del escrito, las advertencias de Heidegger en su carta y prólogo a la obra de William Richardson Trough Phenomenology to Though ${ }^{22}$ para destacar algunas cuestiones elementales.

20 La distinción de las formas del Ereignis como yección-proyección; viraje-contraviraje se han retomado del seminario de Roberto Walton y la obra de von Herrmann previamente citadas.

21 von Herrmann nos dice en su obra «en la unidad de arrojo propiciador-apropiador y de proyecto propiciado-apropiado acontece la esenciación de la verdad del Ser, esenciación a la que Heidegger llama Ereignis». F. W. von Herrmann, op. cit., p. 92

22 M. Heidegger, Carta-prólogo a W. Richardson, Heidegger. Trough Phenomenology to Thought, trad. Irene Borges Duarte, en Anales del Seminario de Historia de la Filosofía, $\mathrm{N}^{\circ} 13$, 
En principio hay que recordar que es preciso entender a qué se refiere el filósofo con la Kehre, ${ }^{23}$ puesto que de ello se desprende el sentido de su camino. Heidegger comenta en el prólogo a la obra de Richardson que la maduración de un complejo temático (Sachverhalt) ${ }^{24}$ a través de un largo tiempo produjo la Kehre. Aquella que de manera pública apareció en la Carta sobre el humanismo en 1947 pero que movía su pensamiento desde una década atrás. ${ }^{25}$ En el protocolo al seminario Zeit und Sein el filósofo específica que «las referencias y nexos que constituyen la estructura esencial del Ereignis han sido elaborados entre 1936 y $1939 » .{ }^{26}$ Por tanto, la Kehre no implica para el autor un cambio en su punto de vista del Dasein al Seyn, sino que remite a la inversión del todo -es decir, del complejo temático- de Sein und Zeit a Zeit und Sein. Allí se funda el discurso del ser, propio del Ereignis. Con esto queremos decir que la Kehre se desarrolla como una instancia particular del pensamiento heideggeriano -independiente e involuntaria, según la interpretación de Heidegger- que fue surgiendo a medida que el programa del filósofo adquiría cierta profundidad y cercanía a la cuestión del origen.

Von Herrmann plantea un sentido de la Kehre diferente de su comprensión habitual, pues este pensador cree que la Kehre tiene un estatuto ontológico, es decir, es la estructura del acaecer, la forma como el ser se da. Von Herrmann sigue

Universidad Complutense de Madrid, Madrid, 1996, op. cit.

23 Tal como la traducción del término Ereignis genera problemas por causa del matiz semántico que se le quiere dar, se dificulta encontrar una traducción del término heideggeriano Kehre que refiera a la carga ontológica que adquiere en los `30. Por tanto, han variado las formas de traducirlo, entre ellas se encuentran las siguientes: «viraje», «vuelta»e «inflexión». El término Wendung «giro», «inversión de marcha» o «cambio de orientación» tiene un sentido similar que también se aplica en algunas lenguas. Para continuar con el criterio previo, a saber, mantener en la narración el término alemán Ereignis, en este caso también utilizamos en el escrito el término alemán Kehre.

24 Este término también sufre la obstrucción semántica de su sentido en la traducción. Irene Borges Duarte plantea que suele traducirse el término Sachverhalt por «estado-de-cosas» [«pertinencia de la cosa» o «condición natural de la cosa»] pero que en la carta de Heidegger al padre Richardson no puede utilizarse esa traducción porque allí «Sachverhalt designa la estructura o conexión estructural de los aspectos de una cosa y la cosa mísma constituída. Es, pues, no tanto un 'estado' sino una dinámica estructural interna, la textura y el comportamiento intrínseco del complejo, su tejido o entramado. Y la 'cosa' en cuestión no es res o Ding, sino lo que da que pensar y hay que pensar. De ahí la traducción de Sache por cosa o tema [causa, motivo, asunto o cuestión]». M. Heidegger, Carta-prólogo a W. Richardson, Heidegger. Trough Phenomenology to Thought, op. cit., p. 12.

25 cf. Carta-prólogo a W. Richardson, Heidegger. Trough Phenomenology to Thought, op. cit., p. 16.

26 M. Heidegger, Zur Sache des Denkens [GA 14], op.cit., p. 52. (Tiempo y Ser, op. cit., p. 63.) 
una línea de interpretación del pensar de Heidegger que inicia una comprensión del todo unitario de la obra y que considera lamentable el estudio exclusivo de alguna de las etapas del autor alemán. La lectura de la Kehre ha genereado la distinción del pensar de Heidegger en dos períodos. Como es común se evalúa la obra del autor y se traza una línea entre el trabajo del primer Heidegger y el del segundo, como si los períodos fueran inconciliables. Al respecto Heidegger aclara en el prólogo al escrito de Richardson que tal distinción sólo puede plantearse a condición de que para abordar el Heidegger II es preciso acceder a lo pensado en el Heidegger I, y que Heidegger I sólo es posible si está contenido en Heidegger II. Ya nos dice von Herrmann que «[...] puede que haya dos momentos en la trayectoria del pensar heideggeriano; pero camino sólo hay uno» ${ }^{27}$ y en su lectura propone una mutación inmanente (immanenter Wandel) de la misma intención que en Sein und Zeit ya se plasmó.

El presente trabajo considera enriquecedora la posición de von Herrmann e intenta, siguiendo esta vertiente de interpretación, ${ }^{28}$ dar cuenta de lo que aquí se plantea como «la estructura conflictiva del Ereignis» a través de la descripción de su génesis y constitución por medio de las problemáticas de la donación y la diferencia ontológica. Respecto a la tesis que aquí se defiende acerca de la continuidad del pensar de Heidegger mencionamos -sólo para indicar un argumento a favor de esta afirmación, puesto que explicarlo demandaría el desarrollo paralelo de otro trabajo- la idea de que la estructura conflictiva del Ereignis es, para nosotros, una reformulación de la composición bidimensional del Dasein. Esta idea propone entender la analítica existencial a partir de una estructura bidimensional que se repite en los ' 30 , transformada de forma tal que en el Ereignis abarca bajo el aspecto de la diferencia ontológica la oscilación de la donación.

Parvis Emad propone una lectura ${ }^{29}$ que coincide con la nuestra porque indica respecto a la aclaración de Heidegger de que "Heidegger I sólo es posible si está contenido en Heidegger II" que la Kehre se entiende cuando se observa que la estructura del Dasein se mantiene y sólo la perspectiva del horizonte trascendental se abandona, incluso en otro parte de su escrito ${ }^{30}$ dice que la estructura del Dasein re-emerge como una estructura transformada. El camino

27 F. W. von Herrmann, op. cit., p. 12.

28 Algunos estudiosos de Heidegger, inspirados en la interpretación de von Herrmann y las explícitas aplaraciones del pensador de la selva negra, siguen la idea de la continuidad y unidad de la obra heideggeriana como Parvis Emad, Frederick Olafson, Richard Polt, entre otros.

29 Cf. P. Emad, «Questioning Richardson's 'Heidegger I y Heidegger II' Distinction and his Response in Light of Contributions to Philosophy» en On the way to Heidegger's Contributions to Philosophy, University of Wisconsin Press, Wisconsin, 2007, p 188.

30 P. Emad, op. cit., p. 189. 
de la ontología fundamental en Sein und Zeit no era para el filósofo el correcto para acceder a la Kehre, es decir, a lo que debe considerarse -en palabras de Emad- como «being's turning relation to thinking» o lo que podría ser «el tránsito al pensar del ser». Para Emad se retiene la estructura del Dasein porque a través del existenciario de la proyección (Entwurf) se concreta el tránsito del pensar en los ensambles del salto (der Sprung) y la fundación (die Gründung). Nuestra idea va un poco más allá del objetivo de Emad, ya que consideramos que la estructura bidimensional del Dasein expresa las dos partes de la donación. Esto se debe a que tanto la develación como la ocultación que el Dasein genera -expuesta en detalle en Sein und Zeit- son el efecto derivado de la donación y sustracción propia del ser, que luego Heidegger expone más claramente en los '30. Ahora bien, dejamos el desarrollo de este argumento para otra investigación porque no podemos pretender abarcar la totalidad del problema -si es que la hay- en un escrito.

Retomando el hilo conductor de la diferencia ontológica y la donación, podemos recordar que Heidegger afirma en la carta a Richardson que a pesar del tránsito en su pensar se mantienen presentes ciertos factores constantes que lo motivan, a saber, la cuestión del ser, la noción de verdad como desocultamiento, el carácter temporal del ser y la tarea descubridora del hombre. Sin embargo, nosotros creemos que luego de Sein und Zeit el pensamiento de Heidegger transfiere el problema del ser al problema de la diferencia ontológica (ontologische Differenz). Por ejemplo en Die Grundprobleme der Phänomenologie, es decir, las lecciones de Marburg de 1927 en las que Heidegger pretendía en un punto completar el programa de Sein und Zeit, el filósofo deja constancia de algunos problemas centrales a trabajar ${ }^{31}$ para concluir la tercera parte de la obra capital. Los contenidos planteados y la propia introducción del curso dejan en claro que las temáticas del tiempo y la diferencia ontológica fundan toda comprensión del ser. De este modo, respecto al objetivo de su trabajo Heidegger dice: «...tenemos que poder efectuar con claridad la distinción entre el ser y el ente para que algo así como el ser se convierta en tema de investigación». ${ }^{32} \mathrm{Si}$ volvemos a los cuatro factores de la carta a Richarson previamente mencionados podemos intuir que estos devienen, en última instancia, en el asunto de la diferencia ontológica puesto que la donación sustraída afecta a cada uno de ellos.

31 Estos son: el problema de la diferencia ontológica, el problema de la articulación fundamental del ser, el problema de las posibles modificaciones del ser en su modo de ser y el problema del carácter de verdad del ser.

32 M. Heidegger, [GA 24] Die Grundprobleme der Phänomenologie, Vittorio Klostermann, Frankfurt am Main, 1989, p. 22. (Los problemas fundamentales de la fenomenología, Trotta, Madrid, 2000, p. 42). 
Hasta ese momento Heidegger había desarrollado el problema del ser por medio del estudio de la constitución existencial del Dasein, es decir, que para acceder al sentido del ser su trabajo partió de un fundamento óntico - tal como lo indica en Die Grundprobleme der Phänomenologie. ${ }^{33}$ A pesar de la naturaleza ontológica de este ente, el filósofo notó que en cierto punto de su investigación lo originario excedía el ámbito trascendental y que, de hecho, la trascedencia no hacía más que acentuar la tendencia a reducir la diferencia. Por este motivo a partir de los '30 Heidegger intenta abordar el problema del ser con un salto por encima de la trascendencia y captar en su unidad el problema de la diferencia ontológica. Esto se resume en la frase de Heidegger: «pensar el ser sin el ente'. La Kehre es la versión abreviada de 'pensar el ser sin la referencia a una fundamentación del ser desde el ente'». ${ }^{34}$ Heidegger explica que la Kehre no quiere decir que al ser le sea inesencial la relación con el ente. Tampoco plantea que el ser deba pensarse por la diferencia -es decir, por el ente-, sino que la diferencia debe ser pensada por el ser porque, en todo caso, el ser es lo que se da y la donación implica la diferencia. Otra ejemplificación de ello en el curso de 1927 dice: «la diferencia ontológica puede aclararse y llevarse a cabo con precisión en la investigación ontológica sólo si el sentido del ser en general se ha traído a la luz explícitamente, esto es, sólo si se ha mostrado cómo la temporalidad hace posible que se distinga entre el ser y el ente». ${ }^{35}$ De acuerdo a nuestra lectura el sentido del ser es que «se da» y el tiempo funda esta donación que despliega la diferencia.

Bajo esta óptica, este trabajo afirma que el fenómeno del Ereignis le permite a Heidegger configurar el problema de la diferencia y su origen en la destinación del ser. A través del Ereignis Heidegger reformular el marco semántico en el que se aprecia el vínculo del hombre con el ser. Esto se debe a que con la Kehre se desplaza el centro del planteo de las condiciones de posibilidad de una apertura al sentido por medio de la «comprensión del ser» hacia el espacio de juego en el cual el ser se despliega como la «verdad del ser».

Ante todo, hay que señalar nuevamente que Heidegger dice en el protocolo al seminario Zeit und Sein que el tiempo es el factor que genera la Kehre, puesto

33 De esta manera Heidegger transmite «La ontología tiene como disciplina fundamental la analítica del Dasein. En ella se funda así mismo el hecho de que la ontología no pueda fundamentarse de una forma puramente ontológica. Su posibilidad misma remite a un ente, esto es, a lo óntico: al Dasein. La ontología tiene un fundamento óntico». M. Heidegger, [GA 24] Die Grundprobleme der Phänomenologie, op. cit., p. 26. (Los problemas fundamentales de la fenomenología, op. cit., p. 45).

34 M. Heidegger, Zur Sache des Denkens [GA 14], op.cit., p. 41. (Tiempo y Ser, op. cit., p. 52).

35 M. Heidegger, [GA 24] Die Grundprobleme der Phänomenologie, op. cit., p. 23. (Los problemas fundamentales de la fenomenología, op. cit., p. 43) 
que a través de él vira la modalidad de acceso al ser. La idea del ser como la presencia de lo presente dispone al tiempo de una forma que funda la donación más allá de la estructura existencial. Es decir, que la relación entre el ser y el tiempo en base a la esenciación disloca el punto de inflexión en el Dasein y dispone lo originario en la copertenencia del Ereignis. Por tanto, como planteábamos al inicio de este apartado la Kehre no implica un cambio en el punto de vista del Dasein al Seyn, sino una reformulación del problema del ser en un plano más amplio que comprende la diferencia y la donación. Para Heidegger la búsqueda de una relación más originaria por medio del tiempo tiene «el carácter de un retroceso [...] que hace necesario dilucidar el 'hacia dónde' y el 'cómo' en el discurso del 'atrás'». ${ }^{36}$ Pensar el Ereignis permite dar este paso atrás y mentar la retirada del ser y lo indeterminado del adónde.

La idea de un fenómeno que abarque el destino del ser como donación admite la posibilidad de estudiar el flujo de las partes del fenómeno en la inmanencia de su tensión, sea en la ocultación como en la desocultación. De esta manera, por un lado, se pueden distinguir las partes de la composición, si se tiene en cuenta la función de cada una en el fenómeno. Y por el otro lado, se puede identificar la unidad de éstas, si se restituye la dependencia de cada una en orden a la correspondencia mutua. Por tanto, la estructura del Ereignis muestra el problema de la diferencia ontológica a partir de la superación de toda visión unilateral y retroensambla su sentido a la manifestación primigenia del ser.

\section{BIBLIOGRAFÍA \\ OBRAS DE MARTIN HEIDEGGER}

_ GA 2/SuZ: Sein und Zeit, Max Niemeyer, Tübingen, 1960 (Ser y Tiempo, trad. Eduardo Rivera, Universitaria, Chile, 1997)

— GA 11: Identität und Differenz - Identidad y Diferencia, edición bilingüe, trad. H. Cortés y A. Leyte, Anthropos, España, 1990

-GA 12: Unterweges zur Sprache, G. Neske, Pfullingen, 1959. (De camino al habla, trad. Yves Zimmermann, Serbal, Barcelona, 1987)

_ GA 14: Zur Sache des Denkens, Vittorio Klostermann, Frankfurt am Main, 2007 (Tiempo y Ser, Tecnos, Madrid, 1999)

_-_- GA 24: Die Grundprobleme der Phänomenologie, Vittorio Klostermann, Frankfurt am Main, 1989. (Los problemas fundamentales de la fenomenología, Trotta, Madrid, 2000)

36 cf. M. Heidegger, Zur Sache des Denkens [GA 14], op. cit., p. 35. (Tiempo y Ser, op. cit., p. 47.) 
GA 56/57: «Die Idee der Philosophie und das Weltanschauungsproblem» en Zur Bestimmung der Philosophie, Vittorio Klostermann, Frankfurt am Main, 1987. (La idea de la filosofía y el problema de la concepción de mundo, trad. Jesús Adrián Escudero, Herder, Barcelona, 2005.)

— GA 65: Beiträge zur Philosophie (Vom Ereignis), Vittorio Klostermann, Frankfurt am Main, 1989 (Aportes a la Filosofía. Acerca del evento, trad. Dina Picotti, Almagesto y Biblos, Buenos Aires, 2003)

Carta-prólogo a Heidegger. Trough Phenomenology to Thought de William Richardson, trad. Irene Borges Duarte, en Anales del Seminario de Historia de la Filosofía, $\mathrm{N}^{\circ}$ 13, Universidad Complutense de Madrid, Madrid, 1996, pp. 11-18.

\section{ESCRITOS DE COMENTARISTAS}

DREYFUS, H. \& WRATHALL, M. A. (Eds.), «Heidegger's later thought», Tercera parte, en A Companion to Heidegger, Blackwell Publish, USA, 2005

EMAD, P., «Questioning Richardson's ‘Heidegger I y Heidegger II' Distinction and his Response in Light of Contributions to Philosophy», en On the way to Heidegger's Contributions to Philosophy, University of Wisconsin Press, Wisconsin, 2007, pp. 186-210.

OLAFSON, F., «The unity of Heidegger's thought» en Guinon, Charles (Ed.), The Cambridge Companion to Heidegger, Cambridge University Press, New Yorck, 1993, pp. 97-121.

POLT, R., The Emergency of Being. On Heidegger's Contributions to Philosophy, Cornell University Press, Ithaca, 2006

SCOTT, CH., SCHOENBOHM, S., VALLEGA NEU, D., VALLEGA A., (Eds.), Companion to Heidegger's Contributions to Philosophy, Indiana University Press, Bloomington, 2001

VALLEGA-NEU, D., Heidegger's Contributions to Philosophy, Indiana University Press, Bloomington, 2003

VON HERRMANN, F. W., La segunda mitad de Ser y Tiempo. Sobre los problemas fundamentales de la Fenomenología de Heidegger, Trotta, Madrid, 1997.

WALTON, R., Material de cátedra del seminario "Los modos del acontecimiento y el horizonte de mundo" dictado en el marco del Doctorado en Filosofía, Universidad de Buenos Aires, 2010. 
LETICIA BASSO MONTEVERDE es becaria del CONICET - Universidad Nacional de Mar del Plata, Argentina.

\section{Publicaciones recientes:}

«Heidegger: lo orgánico y lo artificial en la experiencia de mundo» en CTS Revista Iberoamericana de Ciencia, Tecnología y Sociedad, Universidad de Salamanca - REDES, n 14, Vol. 5, 2010, pp. 93-103.

«Comunidad y Tradición. Aspectos políticos en el Heidegger de los '30» en Logos, Revista Internacional de Filosofía, Universidad La Salle, México D.F., nº 108, septiembrediciembre, 2008, pp. 9-33.

Línea de Investigación:

Investiga - bajo la dirección de Adrián Bertorello y co-dirección de Ricardo Maliandi — la obra de Martin Heidegger de la década de 1930, específicamente la génesis y constitución de la estructura conflictiva del Ereignis.

Dirección postal: Belgrano 2864, $6^{\circ}$ A, CP 7600, Mar del Plata, Argentina.

Dirección electrónica: letibasso@hotmail.com 
